\title{
sit \\ Sobre la supuesta heteronomía explicativa de la biología funcional
}

Gustavo Caponi

\begin{abstract}
茴
RESUMEN

Según un punto de vista muy difundido, y alineado con la concepción nómica de la explicación causal, la biología funcional está sometida a un régimen de heteronomía explicativa en cuyo marco los fenómenos orgánicos deben explicarse causalmente recurriendo a leyes oriundas de la física y la química. En contra de esa perspectiva, la concepción experimental de la causación permite entender la naturaleza de muchas explicaciones biológicas que, sin hacer referencia a leyes causales - físicas, químicas o de cualquier otra naturaleza - se legitiman por el hecho de ponernos en condiciones de controlar experimentalmente fenómenos relativos al funcionamiento y a la constitución de los organismos. Esas explicaciones suponen invariantes locales que muchas veces, pero no necesariamente, podrán llegar a ser caracterizados como instancias de leyes físico-químicas.
\end{abstract}

PALABRAS-GLAVE • Heteronomía explicativa. Invariantes casuales. Leyes causales. Woodward. James.

\section{Advertencia PRELIMinar}

La concepción nomológica-deductiva de la explicación científica, no obstante haber sido delineada por autores que no tenían a las ciencias de la vida como una referencia importante en sus reflexiones epistemológicas, dejó una marca indeleble en la filosofía de la biología. Aludo a la ya larga polémica sobre la existencia de leyes que permitiesen la construcción de explicaciones nomológicas en ciencias de la vida (cf. Lorenzano P., 2011, p. 60). Enfoques más recientes, como el estructuralista (cf. Ginnobili, 2011; Blanco, 2012), han replanteado esa cuestión rechazando, explícitamente, las coordenadas definidas por la aceptación del modelo nomológico-deductivo de explicación (cf. Lorenzano P., 2011, p. . 3). Pero, aun así, gran parte de la discusión continuó desarrollándose bajo la sombra, quizá vaga y menguante (cf. Woodwaard, 2003, p. 4), del modo en el que Popper (cf. 1962 [1934], p. 57) y Hempel (cf. 1979 [1965], p. 235) entendieron a la explicación científica y a las leyes que la vertebrarían (cf. Woodward, 2000).

Así, independientemente de la relevancia que efectivamente debe adjudicársele a otros enfoques, lo cierto es que gran parte de las preguntas planteadas en torno de la 
temática de la explicación y de las leyes biológicas siguen teniendo su raíz en el enfoque sobre el que se perfiló el modelo nomológico-deductivo de explicación; y es también ahí que algunas de las repuestas dadas a esa cuestiones encuentran sus visos de plausibilidad. Por eso, y no por el hecho de querer concederle a esa concepción de la explicación algún privilegio teórico por sobre concepciones alternativas, posteriores o anteriores, en este trabajo, la naturaleza de las explicaciones causales oriundas de la biología funcional, será discutida teniendo como contrapunto a la concepción nomológica de las imputaciones y de las explicaciones causales. Y esta última restricción también debe ser subrayada.

Por el simple motivo de que nuestro tema serán las imputaciones y explicaciones causales propias de la biología funcional, sólo aludiré a la representación de la explicación causal que surge del modelo nomológico-deductivo de explicación; y no a la representación de toda explicación científica que también surge de allí. Aunque Hempel (1979 [1965], p. 347), a diferencia de Popper (1962 [1934], p. 58), no haya identificado la explicación científica con la explicación causal, ni tampoco haya homologado los conceptos de ley científica y de ley causal, como Popper sí lo hizo, en este trabajo sólo será considerada la concepción nómica de la explicación causal: esa que supone que toda explicación causal debe estar articulada por una ley causal. Pero insisto: eso será sólo un contrapunto. Nuestro tema no será ése; sino una tesis más específica que se afirma en dicha concepción nomológica-deductiva de la explicación. Aludo a la postulación de una supuesta heteronomía que caracterizaría a las explicaciones causales que encontramos en ese dominio de las ciencias biológicas que Mayr (1961) denominó "biología funcional".

\section{Delimitación Del PRoblema}

La polémica sobre la existencia de leyes que permitiesen la construcción de explicaciones nomológicas en biología, se centró - por lo general - en la biología evolucionaria; y a veces en la ecología de poblaciones. El conjunto de disciplinas que Mayr (1982, p. 69) englobó bajo el rótulo de "biología funcional", siempre tendió a quedar fuera de discusión; y eso fue así porque, de un modo u otro, se aceptó que allí regía lo que Marcel Weber (2004, p. 28) caracterizó como una heteronomía explicativa. Según dicha tesis, ya tácitamente presente en el propio Mayr (1961) y en Smart (1963), la biología funcional explicaría causalmente los fenómenos y procesos por ella estudiados, aplicando, implícita o explícitamente, leyes causales propias de la física y de la química. Diferentemente de la biología evolucionaria y de la ecología poblacional (Weber, 2004, p. 28), la biología funcional, a la que Weber (2004, p. 3) llama “biología experimental”, avan- 
zaría siguiendo un proyecto de orientación reduccionista (cf. Weber, 2004, p. 24) caracterizado por un uso creciente de leyes físico-químicas.

"Para explicar los fenómenos biológicos", dice Weber (2004, p. 28), "los biólogos experimentales deben aplicar teorías oriundas de la física y de la química”; y, de hecho, cuando se considera el desarrollo de la biología molecular, uno podría sentirse obligado a aceptar esa tesis (cf. Jacob, 1973, p. 200; Roger, 1983, p. 141). Por lo menos a primera vista, la heteronomía explicativa de la que habla Weber parece corresponderse con la que ha sido y sigue siendo el vector de progreso de esas disciplinas biológicas orientadas al estudio, funcional y ontogenético, de toda esa jerarquía de sistemas que va del organismos hasta sus componentes moleculares más simples, pasando por los tejidos, órganos, y sistemas de órganos (cf. Caponi, 2013a, p. 201).

Creo, sin embargo, que aceptar esa idea tal y como Weber la presenta, puede conducirnos a dos errores: ambos solidarios con la concepción nomológico-deductiva de la explicación. El primero de esos errores es el de refrendar la concepción de la explicación causal que dicha idea conlleva: explicar causalmente supondría, ora la referencia directa a leyes causales; ora la referencia a mecanismos cuya operación pueda descomponerse - por lo menos en principio - en múltiples procesos causales que sí sean explicables por alusión directa a leyes de naturaleza causal. El segundo error es el de formarnos una idea epistemológicamente inadecuada, e históricamente inexacta, sobre cómo se explica causalmente en biología funcional y sobre cómo se legitiman las explicaciones, causales, que allí se construyen.

Por eso, en contra de ambas cosas, en estas páginas voy a proponer, en primer lugar, que la explicación causal en biología funcional es más inmediatamente comprensible en términos de la concepción experimental de la causación, y no en términos de la concepción nómica de la causación que anida en la concepción nomológicodeductiva de la explicación causal y que tanto contribuyó a la consolidación de esa última. Será la concepción experimental de la causación, sobre todo en la forma que le dio James Woodward (2003), que nos permitirá entender la naturaleza de esas explicaciones biológicas que, sin hacer referencia a leyes causales físicas o químicas, se legitiman por el hecho de ponernos en condiciones de controlar experimentalmente fenómenos relativos al funcionamiento y a la constitución de los organismos y de los diferentes subsistemas que los componen. Nuestro principal blanco, en pocas palabras y como lo dije, será la tesis de la heteronomía explicativa; que está firmemente anclada en la concepción nomológica-deductiva de la explicación causal.

Me permito señalar, además, que la negación de esa supuesta heteronomía explicativa de la biología funcional que aquí ensayaré, tiene consecuencias que trascienden la propia temática de la causación. Negar la heteronomía explicativa de la Biología Funcional es también afirmar su autonomía epistemológica; y ahí hay más que 
una cuestión puramente verbal; si el vínculo causal entre los fenómenos organísmicos puede establecerse con independencia de la legalidad físico-química, eso implica que el fenómeno organísmico puede darse por explicado antes del establecimiento de esa legalidad. La biología funcional, quiero decir, no tiene que ir necesariamente a la saga de la física y de la química; ni tampoco tiene que esperar que esas disciplinas le concedan sus recursos explicativos. He ahí una autonomía, históricamente ejercida, que no se menoscaba por el hecho de que, eventualmente, la explicación físico-química venga a complementar o a respaldar a la explicación biológica.

Aclaro, por otra parte, que cuando uso la expresión "biología funcional”, no lo hago en el sentido que algunos autores como Rosenberg (2006) y Ginnobili (2011) le dan a ese término. Para ellos, la biología funcional sería aquella que, en lugar de limitarse a indagar la simple composición material de los seres vivos, que es lo que harían la bioquímica y hasta cierto punto la biología molecular, procuraría develar las funciones de las estructuras biológicas (Rosenberg, 2006, p. 25). Yo, en cambio y conforme vengo diciendo, tomo el término "biología funcional" en el sentido que Mayr le ha dado a la palabra: no para oponerlo a "bioquímica" o a "biología molecular"; sino para oponerlo a "biología evolucionaria". Universo disciplinar, este último, que según la acepción que Rosenberg y Ginnobili le dan al término, pertenecería a la "biología funcional". Evidentemente, las dos acepciones del término "biología funcional” son bien diferentes; aunque en algunos casos, pese a la notoria diferencia intensional, sus extensiones se superpongan. No creo, por otra parte, que la opción por la terminología de Mayr, ya clásica y muy reconocida, precise aquí de demasiadas justificaciones (cf. Morange, 2011, p. 17).

La biología funcional, sensu Mayr (1961), es la biología que se ocupa de los fenómenos que ocurren y pueden ser registrados en el plano de los organismos individuales (Caponi, 2012a, p. 96); e incluso en el plano de los componentes más elementales de tales organismos (Jakob, 1973 3 , p. 17). Eso abarca a la fisiología, a la biología del desarrollo, a la biomedicina, y a la propia biología molecular. Disciplinas, todas esas, en las que el método experimental juega un papel destacado; siendo por eso que Weber las engloba bajo el rótulo de "biología experimental". Yo considero, empero, que esa última expresión no corresponde en este caso: también existen abordajes experimentales en la biología evolucionaria (Caponi, 2003; Futuyma \& Bennett, 2009) y en la propia ecología de poblaciones (Park, 1948; Lubchenco \& Real, 1991). Disciplina, esta última, que no encaja en el dominio de lo que Weber llama biología experimental; y tampoco en el modo en el que Mayr caracteriza a la biología funcional (cf. Caponi, 2012a, p. 107).

Considero, por mi parte, que a los fines de este trabajo, la mejor manera de entender la dicotomía entre biología funcional y biología evolucionaria que estoy presu- 
poniendo, es en términos de la distinción entre una biología de fenómenos organísmicos y una biología de linajes (Caponi, 2003, p. 64). La primera, claro, es la biología funcional; pudiéndose considerar a la autoecología como parte de ella (Caponi, 2013a, p. 201). La segunda, mientras tanto, es la biología evolucionaria (Caponi, 2013a, p. 202); que al ser entendida como biología de linajes en general, y no sólo de los linajes como especies y poblaciones, puede considerarse como abarcando también a la biología evolucionaria del desarrollo (Caponi, 2012a, p. 123). Pero aun habría que afinar, generalizar, e incluso potenciar esa distinción, para con ella poder contemplar a la ecología de poblaciones y de comunidades, y también a la ecología de los ecosistemas.

Pienso, en este sentido, que se podría recurrir a la distinción, más general, entre una biología de sistemas y una biología de linajes (cf. Caponi, 2012b). Esta última abarcaría todo lo que acabo de caracterizar como propio de la biología evolucionaria. Y la biología de sistemas abarcaría tanto a las disciplinas biológicas que estudian los procesos ecológicos que ocurren desde el nivel del organismo individual hasta la escala de los ecosistemas; como también abarcaría a aquellas disciplinas que estudian al organismo individual en virtud de sus subsistemas y componentes más simples, incluyendo ahí a las propias moléculas que los integran. La polaridad próximo-remoto podría ser reformulada en términos de la distinción sistema-linaje: las causas remotas son aquellas cuyo accionar se registra en el orden de los linajes; y las causas próximas serían aquellas que actúan en el orden de los sistemas.

Pero todo eso puede ser postergado en este trabajo. Aquí sólo pretendo aludir al conjunto de disciplinas que de hecho Mayr engloba bajo el rótulo de "biología funcional", y Weber bajo el rótulo, a mi entender inadecuado, de "biología experimental". Como ya dije: eso abarca: a la fisiología en el sentido más amplio del término; a la biología del desarrollo; a la genética cromosómica y molecular pero no a la de poblaciones que es parte de la biología evolutiva (cf. Roger, 1983, p. 143; Caponi, 2003, p. 81); a la inmunología; a ciertos dominios de la microbiología; y a la propia biología molecular, sin incluir - claro - a las filogenias moleculares. La bioquímica, además, también podría ser considerada como parte de ese universo disciplinar. Me interesa aquí, por lo tanto, la naturaleza de las explicaciones relativas al orden de las causas próximas en el sentido más estrecho de esa expresión.

En trabajos anteriores ya recurrí a la concepción experimental de la causalidad para, con base en ella, entender la naturaleza de las explicaciones causales que se construyen en ecología de poblaciones y en biología evolucionaria (Caponi, 2013b; 2013c; 2014a). En este último caso refiriéndome a las explicaciones causales formuladas dentro de las coordenadas definidas por la teoría de la selección natural. Y tanto en un caso como en el otro aludí a la presencia de leyes no causales presentes en esas explicaciones. Afirmar que un determinado dominio de ciencia no cuenta con leyes causales 
específicas, o que ciertas explicaciones causales se articulan sin suponer esas leyes, no implica afirmar que esas ciencias estén totalmente desprovistas de enunciados nómicos, de carácter no-causal, que desempeñen otras funciones teóricas relevantes, o que esas explicaciones no supongan leyes de cualquier naturaleza.

Creo oportuno aclarar, por otra parte, que aunque toda la biología funcional, sensu Mayr, está efectivamente permeada por discurso funcional, ahora sí en el sentido que Rosenberg o Ginnobili le dan al término, yo no me ocuparé aquí de esas operaciones cognitivas que puedan caber bajo los rótulos de "explicación funcional" o "análisis funcional". No dudo de que el examen de dichas explicaciones y análisis nos posicione más claramente ante los objetivos cognitivos específicos de la biología funcional, siempre sensu Mayr, que lo que puede hacerlo el examen de las explicaciones causales que allí encontramos y que están presupuestas en muchos de esas explicaciones y análisis de carácter funcional. Pero ya me ocupé de eso en trabajos anteriores; y aquí quiero limitarme únicamente a las explicaciones e imputaciones causales que encontramos en el dominio de ciencia al que estoy aludiendo. Aceptando la idea de que atribuir una función no es otra cosa que imputarle un papel causal a un evento dentro de un proceso mayor debidamente especificado (Caponi, 2012c, p. 38), creo que es necesario complementar esa caracterización de los análisis y explicaciones funcionales, mostrando cómo se articulan y legitiman las imputaciones causales allí implicadas.

\section{ExPLIGAGiones ANómicas}

Se podría pensar que el problema que estoy planteando ya fue resuelto por aquellos autores que, como Darden et al (2006) dejaron de lado el modelo nomológico-deductivo, para comenzar a pensar las explicaciones causales de la biológica en términos de mecanismos. Pero, como Peter Menzies (2012) lo mostró, no es así: aunque ciertamente la imagen de las explicaciones causales de la Biología Funcional que proponen esos autores (cf. Darden et al, 2006, p. 19) es mucho más adecuada, e iluminadora, que la provista por alguna ejemplificación simplista del modelo nomológico-deductivo, hay una cuestión que la referencia a los mecanismos deja sin resolver: la forma que tomarían las explicaciones de cada uno los procesos causales involucrados en el funcionamiento de esos mecanismos (Woodward, 2002, S372). Sin desestimar todos los lucros en términos de compresión de diversos aspectos de la explicación biológica que la idea de mecanismo puede darnos, creo que esa falta puede ser subsanada recurriendo a la idea experimental de la causación (Woodward, 2002, S369).

Los mecanismos, según sus promotores los definen, "son entidades y actividades organizadas de forma tal que generan cambios regulares desde un punto de partida 
o arranque hasta un punto o condición terminal" (Darden et al, 2006, p. 14). Los mecanismos son sistemas o procesos causales articulados y concatenados de forma a producir un resultado que, bajo ciertas circunstancias, es previsible. Eso no sólo da lugar para preguntarnos qué es lo que establece los vínculos causales que deben existir entre los distintos eslabones de dichos procesos (cf. Weber, 2004, p. 29); sino que también invita a buscar explicaciones sobre cómo ciertos procesos o fenómenos pueden causar interferencias y desvíos en el funcionamiento de tales mecanismos. Es decir: necesitamos una idea de la explicación causal que sea anterior a la propia idea de mecanismo (cf. Craver, 2002, p. 72; Glennan, 2009, p. 318); y ahí podemos volver a caer en la idea de la heteronomía explicativa (cf. Darden et al, 2006, p. 20; Bechtel, 2011, p. 537).

Es difícil dejar de lado esa idea sin contar con una alternativa clara a la concepción nómica de la causación; y eso es lo que nos provee la concepción experimental que aquí quiero reivindicar (Woodward, 2002, S375). Ésta brinda una alternativa a la idea de la heteronomía explicativa que, además de ser más radical que la esbozada por Darden et al, puede también incluirla (Menzies, 2012, p. 798). La concepción experimental de la causación da una idea de lo que articula y justifica las imputaciones causales presupuestas en el análisis de los eslabones causales de cualquier mecanismo, que es diferente de la concepción nómica de las imputaciones causales (Woodward, 2002, S371; Craver, 2007 , p. 93). Eso, en lo que atañe al caso específico de la biología funcional, nos exime de aceptar la tesis de la heteronomía explicativa.

Como ya dije, todo el problema de las leyes biológicas, en general y no sólo en lo que atañe a la biología funcional, creció a la sombra del modelo nomológico-deductivo de la explicación. El nudo de la polémica siempre residió en la presunción de que toda explicación causal genuina debía estar, tácita o explícitamente, fundada en una ley causal que satisficiese criterios más o menos próximos a los propuestos por Popper y Hempel (cf. Lorenzano P., 1998, p. 262). La biología evolucionaria, y también otras disciplinas como la ya mencionada ecología de poblaciones, quedaron así en el centro de la polémica porque en el caso de ellas era difícil identificar los enunciados nómicos, de carácter causal, que daban forma y soporte a sus explicaciones e imputaciones causales.

La biología funcional, en cambio, nunca llegó a recibir tanta atención porque se presumía que su supuesta heteronomía explicativa, resolvía todo el problema: sus explicaciones causales se encajarían perfectamente en ese modelo porque, quizá más tacita que explícitamente, ellas estarían articuladas por leyes físicas o químicas de naturaleza claramente causal. Sin embargo, si uno se asoma a las explicaciones causales que efectivamente se construyen en fisiología, en biología del desarrollo, o en dominios biomédicos como la farmacología y la toxicología, se verá que, muchas veces, dichas explicaciones están demasiado lejos de aquello que la tesis de la heteronomía explicativa nos podría hacer esperar. 
No sólo ocurre que esas explicaciones no aluden explícitamente a leyes físicas o químicas específicas; sino que, a menudo, ellas aluden, ora en su explanans, ora en su explanandum, o en ambos, a variables caracterizadas en términos puramente biológicos. En muchos casos, reacciones y procesos fisiológicos son explicados en función de la misma naturaleza, aunque ellas puedan estar afectadas por factores físicos o químicos; pudiendo ocurrir lo mismo con procesos embriológicos, celulares, histológicos, e incluso con respuestas a fármacos y tóxicos de los más diversos tipos. Esas explicaciones establecen conexiones causales sin que se atisbe, ni se considere necesario vislumbrar, cuál sería la ley físico-química, o el conjunto de leyes físico-químicas, que fundaría esos vínculos de causa y efecto.

Además, aunque después se procure, y consiga, profundizar y fundamentar esas explicaciones causales descendiendo a la infraestructura molecular, bioquímica y a veces biofísica, de los procesos biológicos estudiados, realizándose así una démarche que quizá pueda merecer el calificativo de "reduccionista", lo cierto es que ese descenso a lo molecular no tiene por qué redundar en una rectificación de tales explicaciones menos fundamentales, ni tampoco tiene que considerarse como su imprescindible ratificación. Es decir: esos desarrollos de la biología molecular pueden refrendar las explicaciones biológicas más tradicionales; pero eso no implica que las mismas deban ser consideradas como provisorias o inconclusas hasta no recibir dicho respaldo. Eso, junto con la dificultad para identificar las leyes físico-químicas que articularían tales explicaciones, configura un cuadro que no se lleva del todo bien con la idea de heteronomía explicativa. Por lo menos hasta cierto punto, la biología funcional parece capaz de explicar biológicamente: sin tener que explicar física o químicamente.

La teratología nos brinda ejemplos de eso (Ujházy et al, 2012). La perturbación de los procesos de inducción embrionaria, que son los responsables de la diferenciación de órganos en la ontogenia, puede generar distintas malformaciones; y esas perturbaciones pueden ser apuntadas como causas de dichas anomalías sin que para ello sea necesario conocer la base molecular de tales fenómenos (Gilbert, 1994, p. 513-5; Delsol \& Perrin, 2000, p. 88-90). No es que esa base no exista, ni tampoco que su conocimiento no provea una explicación más acabada de esos fenómenos (Gilbert, 1994, p. 527-37). Pero, si se afirma que la estrangulación incompleta de un embrión de salamandra generó un monstruo diencéfalo, y eso se ratifica por una manipulación experimental en la cual se estrangula otro embrión de salamandra de manera tal que se forme otro monstruo con esas características, nuestra explicación causal de ese proceso de teratogénesis será considerada válida y satisfactoria. Aun cuando la base molecular de la inducción embrionaria fuese totalmente desconocida; y aun cuando nadie pretenda apuntar la ley física, o química, de la cual esa relación entre ciertas estrangulaciones del embrión de algunas especies y determinadas malformaciones, sería una instancia o una aplicación. 
Del mismo modo, si se explica el crecimiento de los testículos de los patos que ocurre durante la primavera, diciendo que dicho crecimiento lo genera el aumento de las secreciones de la hipófisis, que es directamente estimulada por la luz solar; esa imputación causal puede ser aceptada y legitimada, aun cuando se ignore la filigrana molecular que permite la estimulación solar de una región cerebral. Esa legitimación puede tomar, otra vez, la forma de una manipulación experimental: si tapamos los ojos de algunos patos, y eso impide el crecimiento de sus testículos, nuestra explicación causal quedará reforzada (cf. Delsol \& Perrin, 200o, p. 88-90). Ese refuerzo aumentará si creamos varios grupos control en los que los ojos de los patos son tapados por periodos más o menos largos; y eso se refleja en diferencias en el crecimiento de los testículos que son proporcionales a la duración de la obstrucción, o al bloqueo mayor o menor de la luz solar que ella ejerce.

Tanto aquí como en caso anterior, no se supone ninguna ley físico-química de la cual el vínculo causal apuntado sea una instancia; y es la posibilidad de control experimental la que nos lleva a aceptar que ese vínculo existe. No hay una ley física que vincule aumento de luz y aumento en el tamaño de los testículos de los patos: pueden existir, en todo caso, leyes causales de naturaleza físico-química que expliquen cada uno de los eslabones del mecanismo; pero no es el conocimiento de dichas leyes lo que justifica la imputación causal "en condiciones normales, la luz solar aumenta el volumen de los testículos de estos patos". Lo que la justifica es la posibilidad de usar esa regularidad como receta para manipular el crecimiento de esos órganos en dichos animales. Una receta que sería muy importante para una industria de paté de testículo de pato; como seguramente ya lo es para la agricultura la correlación constante entre velocidad germinativa y temperatura que se verifica en las diferentes especies de semillas.

Desiderio Papp la explicaba así: "La velocidad germinativa del grano de trigo depende de la temperatura y alcanza su máximo a $28^{\circ}$; por debajo de $5^{\circ}$ y por encima de $37^{\circ}$, la velocidad es nula" (Papp, 1980, p. 178). Eso configura "una curva bien determinada" que será análoga a la que se den con otros granos; aun cuando los extremos de máximas y mínimas varíen en cada caso. Así, conociendo cuál es esa curva en una determinada semilla, podremos controlar o prever su velocidad de germinación, manipulando o midiendo la temperatura en la que ella se encuentra. Años más fríos, podemos preverlo, nos darán cosechas más tardías; y, llegado el caso, imputaremos ese retraso al frio, aun cuando no conozcamos la ley físico-química que explique esa relación causal de la cual, pese a todo, no dudamos.

Pero, si existe un ejemplo de explicación causal biológica que claramente no encaja, ni en la idea de heteronomía explicativa, ni tampoco en el modelo nomológicodeductivo en el que esa idea se recuesta, ese ejemplo es el de la explicación de las enfermedades infecciosas. Tal el caso de la explicación bacteriológica de muchas úlceras 
gástricas (Thagard, 1999, p. 59-61); que fue propuesta y aceptada bajo el imperio de la biología molecular, pero atendiendo a coordenadas típicas de la microbiología clásica: la microbiología de Pasteur y de Koch (cf. Gradmann, 2006, p. 88-90). Quizá con más imaginación que rigor, la explicación del aumento de tamaño de los testículos de los patos, o la explicación de la velocidad germinativa de una semilla, podría presentarse de una forma que, a primera vista, superficialmente, encaje en el esquema del modelo nomológico-deductivo de explicación; y después hasta se podría sugerir una relación de los invariantes fisiológicos allí implicados, con algunas leyes causales físicas o químicas. Ya en el caso de la explicación de las enfermedades infecciosas eso parece casi imposible; y mucho más innecesario.

En la década que va de 1985 a 1995, los médicos australianos Robin Warren y Barry Marshall consiguieron mostrar que Helicobacter pylori era el agente responsable de muchas de esas úlceras en virtud de tres conjuntos de datos:

(1) Evidencia clínica y epidemiológica de la asociación entre dicha bacteria y esa patología;

(2) éxito en la producción experimental de la úlcera por inoculación de cepas puras, cultivadas experimentalmente, de la bacteria imputada; $y$

(3) evidencia experimental y clínica creciente de cura de la úlcera por el uso de un antibiótico específico (cf. Thagard, 1999, p. 62-4).

Es decir, la úlcera se puede producir inoculando Helicobacter pylori; y se puede curar eliminando a ese agente. Nadie precisa de ninguna ley causal, y menos de una ley física o química, para justificar las imputaciones causales que a partir de ahí puedan formularse sobre casos clínicos concretos.

No se trata de poner en duda de que, en ultimísima instancia, las regularidades causales allí implicadas sean la manifestación local de regularidades causales más amplias, y fundamentales, de carácter físico-químico: desde un punto de vista ontológico, todos somos fisicalistas. Lo que importa es que, en casos como esos, la explicación causal puede prescindir de la referencia a esas regularidades mayores: la convicción ontológica no llega a traducirse en exigencia epistemológica. La posibilidad de controlar experimentalmente tales fenómenos por la manipulación de variables específicamente biológicas da soporte y fuerza explicativa a esos análisis causales, aun cuando ellos no tengan fundamento legal de corte físico-químico. En la fisiología, en la biología del desarrollo, en la teratología, en la microbiología, etc., la experimentación llega antes que cualquier ley causal físico-química. En ellas es la experimentación la que distribuye e instituye las imputaciones y las explicaciones causales (cf. Baedke, 2012, p. 170). 


\section{LA GONGEPGIÓN EXPERIMENTAL DE LA EXPLIGAGIÓN GAUSAL}

"La característica distintiva de las explicaciones causales", afirma James Woodward (2003, p. 6), es que ellas "ofrecen información potencialmente relevante para la manipulación y el control: ellas nos dicen cómo, estando nosotros en condiciones de alterar el valor de una o más variables, podríamos modificar el valor de otras". "La idea de hacer", ya lo decía Paul Valery (2002 [1944], p. 54.9), "es la primera y más humana. Explicar es describir una manera de Hacer: es re-hacer con el pensamiento". Eso lo ilustran las explicaciones en las que recurrimos al principio de Arquímedes para dar cuenta del empuje que padece un cuerpo inmerso en un líquido: esas explicaciones nos dicen cómo modificar esa fuerza, ora alterando el volumen del cuerpo, ora alterando la densidad del líquido. Pero eso también se cumple cuando nuestras explicaciones aluden a fenómenos que escapan a toda posibilidad de manipulación (Woodward, 2009, p. 235). Tal como ocurre cuando citamos una erupción del Vesubio para explicar la destrucción de Pompeya.

"La erupción de un volcán y la destrucción de una ciudad", conforme decía Von Wright (1980, p. 94), "son dos eventos sumamente complejos"; y "en cada uno de ellos cabe discernir diversos acontecimientos o fases, y distintas conexiones causales entre ellos". Siendo esas conexiones causales particulares las que satisfacen, cada una de ellas separadamente, la concepción experimental de la causación. Tal "el caso de una piedra que, al caer, alcanza a un hombre en la cabeza y lo mata"; o incluso el derrumbe del "techo de una casa bajo un determinado peso" (Von Wright, 1980, p. 94). Y también la circunstancia de "que un hombre no pueda tolerar el calor por encima de una temperatura en particular" (Von Wright, 1980, p. 94). "En todos esos casos", señalaba Von Wright (1980, p. 94), "tienen lugar relaciones causales que nos resultan familiares por experiencia y en las que el factor-causa satisface típicamente el requisito de ser manipulable".

De cualquier manera, los fenómenos que estudia la biología funcional están, todos ellos, al alcance de nuestra capacidad de manipulación y experimentación; y aunque existen algunos dominios de ese campo de las ciencias de la vida en los que el método epidemiológico substituye al experimental, lo cierto es que la mayor parte de la biología funcional es biología experimental. No será por ese lado que encontraremos algún obstáculo que impida pensarla en función de la concepción experimental de la causación. Pero para entender esta última concepción - o mejor: para sacarla de la esfera de nuestro saber pre-teórico, que es donde ella está profundamente incrustada, y traerla a la esfera de las tesis filosóficas, explícitamente formuladas -, podemos comenzar con un ejemplo que no será de biología. Aun cuando los ejemplos que dimos en la sección anterior son también ilustraciones claras de esa forma de entender las imputaciones y las explicaciones causales. 
Imaginemos que estamos manipulando una vieja radio que ya pasó por muchos y muy descuidados arreglos. Un de los cuales, incluso, resultó en un reposicionamiento del control del volumen cuya ocurrencia inicialmente nosotros ignoramos; siendo que como resultado de esa modificación, dicho potenciómetro ahora opera de modo contrario al habitual. En esa radio miserable, para aumentar el volumen es necesario mover el botón en sentido anti-horario. Por eso nos desconcertamos cuando, al intentar subir el volumen moviendo el control en sentido horario, obtenemos el resultado contrario. Eso, incluso, nos deja momentáneamente con la sensación de haber movido el dial. Los dos únicos controles de ese viejo aparato son del mismo tamaño y ya no cuentan con ninguna indicación sobre función. Con nuestro movimiento, pensamos por un instante, podríamos estar alejando al dial del ponto de sintonía; y no subiendo el volumen, que era lo que habíamos querido hacer.

Esa impresión hasta llega a reforzarse porque, al mover el botón en sentido antihorario - es decir: en el sentido en el que habitualmente el volumen disminuiría si ese fuese su control - la intensidad del sonido vuelve a subir. Podríamos muy bien estar ressintonizando la señal de la cual habíamos comenzado a apartarnos. Pero esa idea, que apenas se nos pasa por la cabeza, se esfuma rápidamente; porque la relación entre el volumen y el movimiento de ese control no sigue la pauta que debería esperarse de un dial: cuanto más amplio es nuestro movimiento en sentido anti-horario, más alto es el volumen. La sintonía, en cambio, permanece constante, aunque ese movimiento llegue hasta el extremo máximo al que dicho control puede llegar si movido en sentido anti-horario. Una sintonía, no lo olvidemos, tiene un ponto óptimo, del cual nos apartaríamos fuese cual fuere la dirección en la que el dial es movido.

Por otro lado, la relación entre el volumen y los movimientos del control que manipulamos, es regular: prácticamente constante. Salvo la perturbación que puede producir un cambio en la posición del aparato, y fuera del efecto ocasionado por una $u$ otra interferencia, siempre que movemos ese control en sentido anti-horario, el volumen aumenta, disminuyendo gradualmente hasta el silencio, cuando el movimiento es en sentido horario. Más aún: la relación entre ese movimiento y el nivel del volumen guarda una proporción que también es bastante regular. Cuanto más amplio y más rápido es el movimiento del potenciómetro, en un sentido o en otro, mayor y más brusca es la alteración del volumen. En cambio, si el movimiento es lento, esa alteración sonora también ocurrirá lentamente; y es ahí, cuando establecemos esa correlación (hasta donde pudimos ver) invariante entre nuestras manipulaciones de ese botón y el volumen sonoro, que nuestras dudas desaparecen. Ese botón, concluimos suspirando, sólo puede ser un control de volumen que, por alguna razón desconocida, funciona de modo opuesto al habitual. 
Podemos no estar en condiciones de explicar una relación causal. Podemos ignorar cómo, por la mediación de cuál mecanismo, las posiciones de un botón determinan el volumen de sonido emitido por una radio. Pero eso no nos deja sin fundamento para considerar que los movimientos en sentido horario y anti-horario de ese botón causan los cambios de volumen. Tal como ocurrió, por otro lado, con la función del páncreas: el papel causal de ese órgano en la digestión de la gordura fue establecido, aun sin que supiésemos cuáles eran los mecanismos fisiológicos y bioquímicos que explicaban la mayor presencia de gordura no digerida en la materia fecal de los perros en los cuales se impedía el funcionamiento de esa glándula (cf. Romo, 2006, p. 1०3). Que no podamos explicar una relación de causa-efecto no implica que ella no pueda ser invocada para operar, ella misma, como clave de la explicación causal de un evento.

Que un agricultor ignore qué es lo que explica la relación entre temperatura y velocidad de germinación, no lo impide de explicar la tardanza en la germinación de su sembradío después de un invierno demasiado frio. Incluso si no hubiese otro conocimiento sobre esa correlación que fuese más allá de la evidencia experimental, provista por nuestra capacidad de controlar experimentalmente la velocidad de germinación manipulando la temperatura en la se encuentran las semillas, aun así esa explicación sería válida. Como es válido atribuir una úlcera al accionar de Helicobacter pylori, aun cuando no sepamos cómo es que esas bacterias dañan el tejido gástrico. Podemos desconocer el mecanismo de la lesión y aún decir: la infección por Helicobacter pylori es su causa. La cura por el antibiótico nos dará la razón.

O volviendo al ejemplo de la radio, que yo ignore, como de hecho ignoro, el mecanismo que permite que los potenciómetros regulen el volumen de los aparatos de audio, e ignore también por qué ese viejo y maltrecho receptor tiene su control del volumen invertido, no implica que yo esté impedido de explicar un aumento del volumen de ese aparato, diciendo que eso ocurrió porque yo mismo moví la perilla indicada en dirección anti-horaria. Si alguien me pregunta por qué el volumen aumentó, podré aun responder, impávido: "Porque moví el control del volumen en sentido antihorario". Estaré dando una impecable explicación causal de lo acontecido. Una explicación que podrá ser corroborada mostrándose que, si volvemos ese controle para su posición anterior, el volumen también decrece.

Pero, lo que ahí funcionará como prueba crucial de la corrección y pertinencia de esa explicación causal es que, repitiendo el movimiento en sentido anti-horario del control en cuestión, el volumen aumentará nuevamente. "En este viejo y maltratado aparato, el volumen crece si el botón negro es movido en sentido anti-horario y decrece si ese movimiento se hace en sentido contrario". He ahí un principio de funcionamiento específico de ese receptor particular; un principio que se instaló como base de explicaciones causales del comportamiento de ese aparato. No de todos los aparatos 
de radio, pero sí de ese aparato enclenque que tengo entre las manos y que es el único con el que cuento, en ese momento, para escuchar el inminente match Argentina-Brasil. Llegamos así a un tema clave.

Llegamos a una noción que es crucial para la concepción experimental de la causación: aludo a eso que Woodward (2002, S370; 2003, p. 14-5) llama "invariancia” o "invariante" (cf. Psillos, 2002, p. 182-3). Los estados de una variable sólo pueden ser controlados por intermedio de la manipulación de los estados de otra variable, que sea realmente distinta de la primera, si entre esos estados existe una asociación constante tal que pueda preverse la modificación que ocurrirá en la variable controlada en virtud de nuestro conocimiento de la modificación que introduciremos en la variable de control (Woodward, 2010, p. 291-2). Podemos afirmar que existe una relación causal entre un cambio ocurrido en una variable $X$ y un cambio ocurrido en otra variable $Y$, solamente bajo la hipótesis de la existencia de una relación virtual, latente, pero mínimamente constante, invariante, entre los cambios y estados de $X$ y los cambios y los estados de $Y$ (Woodward, 2003, p. 15-7).

Cuando manipulábamos la miserable la radio de nuestro ejemplo, el descubrimiento de que aquel potenciómetro, pese a su comportamiento inicialmente desconcertante, era el control del volumen y que el nivel de éste dependía de las posiciones de aquél, coincidió el establecimiento de este invariante: si movemos este control en sentido anti-horario, el volumen aumenta, y lo movemos en sentido horario, el volumen disminuye. En el funcionamiento de ese castigado aparato, esa anomalía era una regla, una constante; y era esa constante, que no deja de ser una regularidad específica del comportamiento de esa radio, que daba soporte a la certeza de que los cambios de volumen eran producidos por nuestras manipulaciones de ese control. "Las regularidades invariantes", conforme dice Jani Raerinne (2013, p. 847), "describen relaciones de dependencia que pueden ser usadas para manipular cosas. Una regularidad invariante describe que pasaría con el valor de una variable presente en una regularidad o relación, si el valor de una o más variables fuese alterado por intervención o manipulación”.

Hay una regularidad invariante entre ciertas intervenciones, mecánicas o químicas que pueden hacerse en un embrión, y ciertas malformaciones que se manifestarán en un momento posterior de la ontogenia. Hay también una regularidad invariante entre la temperatura a la que se somete una semilla y su velocidad de germinación; y como Papp nos mostró, ella hasta puede expresarse en una curva matemática constante para cada especie o variedad de semilla. Hay, por fin, una regularidad invariante que permite correlacionar la mayor estimulación lumínica padecida por un pato, con el volumen que pueden alcanzar sus testículos; y esto es así aunque poco sepamos del mecanismo fisiológico que intermedia entre el input lumínico y el output testicular. 
Las leyes causales como el principio de Arquímedes son, claro, invariantes: son un tipo de invariantes; y eso nos lleva a aceptar que: "en lugar de pensar a todas las generalizaciones causales como siendo leyes", debemos entender a "las leyes como siendo solamente un tipo de generalización invariante" (Woodward, 2003, p. 17). Eso es así porque la noción de invariante no está necesariamente vinculada a la de universalidad, ni tampoco está vinculada a los sintomas de nomicidad que suelen citarse en los análisis estructuralistas (cf. Lorenzano P., 2007, p. 195). Las regularidades invariantes pueden ser de validez puramente local (Woodward, 2003, p. 17). Pueden estar referidas a ciertos linajes particulares de seres vivos, como vertebrados en general o patos de ciertas especies. Pueden referirse a ciertas úlceras; y si se trata de la relación entre temperatura y velocidad de germinación, se puede decir que hay un invariante para cada variedad de semilla.

Más aún, los invariantes pueden estar referidos a un único caso; como en el ejemplo de nuestra radio. Ahí nuestras imputaciones causales no se basaron, ni siquiera, en la presuposición de que en todas las radios en las que el potenciómetro del volumen estuviese posicionado de una determinada forma, la intensidad del sonido aumentaría si dicho control fuese movido en sentido anti-horario. Lejos de eso, nuestras explicaciones causales de las sucesivas alteraciones del volumen, se basaron en un invariante referido sólo a ese aparato: en él, el volumen aumentaba si el control respectivo era movido en sentido anti-horario y decrecía si el movimiento ocurría en el sentido opuesto. Hasta donde queríamos saber, eso nos bastaba.

Los estados de cosas conectados por un invariante causal no tienen por qué ser comprendidas como ejemplos de clases naturales: ellas pueden ser designadas por nombres propios o por descripciones definidas (cf. Raerinne, 2013, p. 847). No es necesario, además, que esos invariantes tengan algún grado significativo de integración teórica (cf. Woodward, 2003, p. 17), ascendente o descendente: no es imprescindible que se deduzcan de un cuerpo mayor de teoría, aunque en muchos casos eso sea un objetivo cognitivo pertinente; ni tampoco tenemos que esperar que cumplan algún papel de integrador o sistematizador dentro de un marco conceptual determinado. Esto último es algo que exigimos de las leyes, incluso de las que no son causales (Lorenzano, 2007, p. 208); pero no tenemos por qué exigirlo de toda generalización causal. Éstas pueden valer para un único sistema y solamente durante el lapso de tiempo en el que ese sistema exista, o presente la configuración que lo hace comportar de una determinada manera.

Se puede pensar, así, en un amplio espectro de invariantes causales que iría de aquellos más restrictos, que se aplican a un sistema particular e, inclusive ahí, solamente en algunas circunstancias, hasta los más generales y de aplicación más universal; que son los que llamamos "leyes causales". Las clausulas ceteris paribus que definen 
la aplicación de dichas leyes podrán ser, a su vez, más o menos restrictivas; y de eso dependerá la ubicación de las leyes que las incluyan, en los rangos superiores del espectro de universalidad (Woodward, 2003, p. 242). Cerca del primer extremo estaría el olvidable invariante de nuestra radio; y cerca del otro extremo estaría el glorioso principio de Arquímedes. Aunque, importa subrayarlo, esa universalidad no dependa sólo de la extensión de la clase de objetos a la que ella se aplica; sino también de la variedad de circunstancias en la que ella se cumple (Woodward, 2003, p. 257).

La relación entre, de un lado, el volumen de un cuerpo y la densidad del liquido en el cual él está inmerso, y, del otro lado, el empuje que dicho cuerpo padece, es más contante y estable que la relación entre los movimientos de un potenciómetro en una radio y sus cambios de volumen sonoro. Si la entrada de energía en la radio está decreciendo, podrán ocurrir disminuciones de volumen totalmente independientes de las posiciones de ese potenciómetro; y si la señal captada es irregular ocurrirán oscilaciones de volumen cuya intensidad tampoco podrán explicarse por dichas posiciones. Ni que hablar, por otra parte, de todos los desperfectos internos al circuito de la radio que pueden perturbar su funcionamiento, conspirando contra el cumplimiento de nuestro humilde invariante. Éste es definitivamente menos estable, menos confiable, que el principio de Arquímedes.

Las leyes físicas que podamos usar para explicar causalmente el modo en que se conectan los movimientos de un potenciómetro y el nivel del volumen emitido por una radio, también serán, ciertamente, más estables, más profundas y más explicativas, que el invariante "si el botón negro se mueve en sentido anti-horario el volumen de esta radio aumenta". Éste último podría dejar de cumplirse por muchas y muy variadas contingencias; esas leyes, en cambio, se continuarían cumpliendo aun en esas circunstancias y hasta nos servirían para explicar lo ocurrido. Pero, que esas leyes sean más profundas, más estables, y hasta más explicativas que nuestro módico saber sobre cómo controlar el volumen de una radio, no significa, como ya dije, que este último no pueda citarse para explicar causalmente una disminución o un aumento de volumen.

El enfoque experimental de la causalidad, permite entender, en efecto, "como una generalización es capaz de desempeñar una función explicativa aunque eso ocurra solamente dentro de cierto dominio o en un intervalo espaciotemporal limitado, teniendo excepciones fuera de ahí" (Woodward, 2003, p. 240). Posibilidad esa que es crucial para reconocer el carácter causal de las explicaciones que encontramos en ciencias especiales como esas que componen el universo de la biología funcional. Eso no lleva a negar que en física o en química existan "generalizaciones que sean legítimamente consideradas como leyes" (Woodward, 2003, p. 240); pero nos permite pensar que la explicación causal puede construirse en base a regularidades causales que no presentan los atributos, típicamente nómicos, de universalidad y/o integración teórica. 
Es claro, por otra parte, que el reconocimiento de eso, no implica negar que la unificación teórica sea un valor cognitivo importante. Un invariante causal aislado, aunque resulta muy estable en su área de aplicación, constituye un conocimiento menos acabado que un invariante causal con la misma estabilidad que pueda considerarse, en algún sentido, como una especificación de un principio más general. Restaría aun discutir cómo se relacionan esos dos valores cognitivos que son la integración teórica y la estabilidad bajo intervenciones: ¿cuál es más importante?; o ¿en qué contextos uno prima sobre el otro? Pienso que la cuestión debería examinarse teniendo en cuenta la distinción entre ciencias baconianas y ciencias galileanas propuesta por Kuhn (cf. 1977, p. 32). En el desarrollo efectivo de estas últimas la unificación teórica parece tener más valor que la estabilidad bajo intervenciones; con las primeras parece ocurrir lo contrario.

\section{Distribuciones Gontingentes y REgUlaRidAdes GAUSAleS}

La distinción que Kenneth Waters (1998) trazó entre dos tipos de generalizaciones biológicas, las distribuciones contingentes y las regularidades causales, puede ser refrendada y clarificada a partir de esa idea de invariante que Woodward pone en el centro de su concepción de las explicaciones e imputaciones causales. Pero ella, la distinción de Waters, también puede darnos una oportunidad para formular con mayor claridad las tesis de Woodward; mostrando cómo es que ellas permiten reconocer la capacidad de legitimar y articular explicaciones causales que poseen ciertas generalizaciones biológicas que, desde el punto de vista de la concepción nómica de la causación, nunca podrían ser reconocidas como el elemento estructurador fundamental de ningún explanans causal.

En cierto sentido, las distribuciones contingentes a las que Waters alude, son a las regularidades causales, lo que las leyes de asociación de Nancy Cartwright son a las leyes causales como el principio de Arquímedes. Las leyes de asociación son esos enunciados que "dicen cuán frecuentemente dos cualidades o dos cantidades están asociadas"; pero sin establecer ningún vínculo causal entre ellas (Cartwright, 1983, p. 21). Las distribuciones contingentes, por su parte, informan cuán frecuentemente dos cualidades o cantidades biológicas están asociadas; sin tampoco establecer un vínculo causal entre ellas. Las mismas están articuladas por cuantificadores como todos, ningún, casi todos, raramente o en general.

Las generalizaciones "casi todos los urubúes son negros" y "el albinismo es infrecuente entre los urubúes", son ejemplos de esas distribuciones contingentes. Ya la generalización "la ausencia de melanina causa albinismo" es una regularidad causal, 
como también lo son las afirmaciones "el incremento de la actividad física acelera el ritmo cardíaco" y "la exposición prolongada al sol oscurece la piel”. Mientras tanto, la afirmación "en general, los descendientes de japoneses que viven en Brasil tienen la piel más oscura que sus parientes de Canadá” es una distribución contingente, o sea, la descripción de un hecho que pide una explicación, que quizá pueda ser dada por esa regularidad causal que vincula la exposición al sol con el oscurecimiento de la piel.

Las distribuciones contingentes son objetos muy familiares y poco problemáticos para la Filosofía de la Ciencia. Generalizaciones como "todos los cuervos son negros" son los ejemplos típicos de esa universalidad accidental, carente de contenido causal y de poder explicativo. Siempre fue cómodo contraponerlas a las leyes para así resaltar el valor explicativo y el eventual contenido causal de los enunciados nómicos. El problema está en las regularidades causales. Por un lado, es obvio que ellas no son enunciados universales como el principio de Arquímedes. "el incremento de la actividad física acelera el ritmo cardíaco" y "la exposición prolongada al sol oscurece la piel" son generalizaciones que valen sólo para algunos taxones. Es decir: sólo se aplican a ciertas entidades particulares; y por eso su estatuto de leyes fue reiteradamente negado (Hull, 1986). Pero, como Waters (1998, p. 18-20) señala, ellas tienen peculiaridades que las aproximan a las leyes. Papp (1980, p. 178), por ejemplo, tomó la regularidad causal que vincula temperatura y velocidad de germinación, como si ella fuese un ejemplo de ley biológica; y eso es entendible.

Las generalizaciones causales tribuyen a determinados objetos disposiciones para comportarse de una determinada manera; soportan predicciones contrafácticas; y hasta puede decirse que su validez no está espaciotemporalmente restringida. La primera de esas peculiaridades es bastante obvia. Cuando decimos que la actividad física incrementa el ritmo cardíaco, le atribuimos al corazón una pauta de reacción y formulamos una predicción condicional del tipo: "si corremos, nuestro ritmo cardíaco se acelera". Enunciado ese que no sólo será invocado para explicar la aceleración del ritmo cardíaco sufrida por Tomatis después de correr para cruzar la calle bajo la lluvia; pero que también estará en juego cuando se afirma que Pichón habría sufrido síntomas semejantes si hubiese emprendido la misma carrera en lugar de haberse quedado para pagar la cuenta en el bar de la estación. Ya la no restricción espaciotemporal de ese tipo de enunciados no parece tan fácil de aceptar. Pero creo que la reconocemos al suponer que, cumplidas ciertas cláusulas ceteris paribus, la correlación entre velocidad de germinación y temperatura se mantendrá más o menos constante en todas partes. Vale en la Tierra y valdría en Marte. Malgré Ray Bradbury.

Lo cierto, por fin, es que las regularidades causales apuntadas por Waters, que son sólo un tipo particular de invariante causal, son permanentemente utilizadas en la articulación de explicaciones causales que pueden ser representadas por un esquema 
que no está demasiado lejos del modelo nomológico-deductivo. Si aceptamos que la actividad física incrementa el ritmo cardíaco y constatamos que el ritmo cardíaco de Tomatis se fue incrementando a medida que transcurría la prueba de capacidad aeróbica a la que se sometió después del episodio en la terminal de Santa Fe, y que ese aumento estaba asociado al incremento en la intensidad de los ejercicios; entonces será difícil rechazar la validez de esta explicación causal:

\section{Explanans}

REGULARIDAD CAUSAL:

la actividad física incrementa el ritmo cardíaco.

CONDIGIÓN INIGIAL/DESGRIPGIÓN DE LA GAUSA EXPLICANTE:

En el lapso de tiempo $t$, Tomatis incrementó la intensidad de su actividad física.

\section{Explanandum (descripción del efecto explicado)}

En el lapso de tiempo $t$, el ritmo cardíaco de Tomatis se incrementó (proporcionalmente a ese incremento de la intensidad de la actividad física por él desplegada).

El isomorfismo entre esa explicación, basada en una simple regularidad causal biológica, y una posible explicación fundada en una ley causal, obedece a una razón importante. Ambos tipos de explicaciones son explicaciones causales articuladas en virtud de eso que Woodward llama "invariantes causales". Las leyes causales, como vimos, son invariantes de aplicación más irrestricta, y las regularidades causales a las que se refiere Waters son invariantes de aplicación restricta. Pero, aún así, estas últimas ponen en evidencia relaciones causales que cumplen perfectamente con aquello que la concepción experimentalista de la causación nos lleva a esperar de un vínculo causal. Que la actividad física incrementa el ritmo cardíaco, y que el aumento del ritmo cardíaco de Tomatis que estamos registrando, se debe al aumento de su actividad física, son cosas que podemos corroborar por medio de manipulaciones relativamente simples. Podemos disminuir ese ritmo cardíaco haciendo que Tomatis se siente, y podemos volver a incrementarlo, gradualmente y de forma controlada, en virtud de un nuevo aumento, gradual y también controlado, de esa actividad física.

Pero, si hay algo que la distinción de Waters entre distribuciones contingentes y regularidades causales permite ver con claridad, es la importancia de la idea de invariancia bajo intervenciones (Woodward, 2003, p. 17). Ella es central para caracterizar un invariante causal (Baedke, 2012, p. 156); y las distribuciones contingentes son ejemplos posibles de invariantes que no son estables bajo intervenciones: que se rompen 
ante cualquier tentativa de usarlos como pauta de ordenadora de una operación de control técnico o experimental. "Cuando una relación es invariante bajo por lo menos algunas intervenciones", dice el propio Woodward (2003, p. 16), "ella es potencialmente usable con propósitos de manipulación y control”; y eso muestra que ella, diferentemente de lo que ocurre con las distribuciones contingentes, reamente alude a una relación causal. Woodward explica esa idea de la siguiente manera:

Supongamos que observamos una asociación o una correlación entre C y E. Si cada intervención que cambia el valor de $\mathrm{C}$ rompe cualquier correlación entre Cy E (esto es: C y F devienen no correlacionadas bajo esa intervención), no será posible usar $\mathrm{C}$ para controlar o manipular E, y no consideraremos la relación entre $\mathrm{C}$ y E como causal. Si, por el contrario, la asociación entre C y E continúa vigente (o invariante) bajo por lo menos algunas intervenciones que cambian $\mathrm{C}$, entonces (si los cambios en C están asociados con diferentes valores de E) estaremos habilitados para usar de esa estabilidad para producir cambios en E para producir cambios en C. Más aún, siendo otras cosas igual, cuánto mayor el espectro de esos cambios bajos los cuales la relación es invariante, más ella será explotable para propósitos de manipulación y control (2003, p. 241-2).

Por mi parte, creo que una versión modificada del juego de las bolitas al que Sober (1984, p. 99) alude para explicar la diferencia entre un proceso causal como la selección for y un proceso no causal como la selección of, también sirve para mostrar esa distinción entre correlaciones invariantes bajo intervenciones y correlaciones que no lo son. No se trata de una casualidad. La idea de selección of alude a la consecuencia de un proceso causal: alude a una distribución contingente. La selección for alude a lo que pauta, o rige, un proceso causal: alude a un invariante. Pero eso tiene que ver con biología evolucionaria y aquí hablamos de biología funcional; hablamos de invariantes que se registran en el plano de las causas próximas y no de aquellos que se registran en el plano de las causas remotas. Vamos, entonces, a nuestra versión del juego.

Imaginemos que tenemos una bolsa de bolitas de madera que incluye bolitas de color verde de un centímetro cúbico y bolitas de color rojo de un centímetro cúbico y medio; y que dado que no tenemos mejor cosa para hacer porque la radio finalmente se rompió, las hacemos pasar por una suerte de colador que sólo deja pasar a las primeras. Si hacemos eso, en la distribución final de las bolitas se cumplirán dos correlaciones: (1) las bolas rojas son retenidas por el colador pero las verdes no lo son; y (2) las bolas grandes son retenidas por el colador pero no las chicas. Más aún: si repetimos la operación varias veces, esas correlaciones se mantendrán y podremos caracterizarlas como invariantes del comportamiento del sistema bolitas-colador. Existe, sin embargo, 
una diferencia obvia entre (1) y (2): sólo esta última es una correlación, o un invariante, realmente causal. Es decir: mientras la correlación entre color y posibilidad de pasar o no por el colador es accidental, no-causal, la correlación entre el tamaño y esa posibilidad sí es causal. Eso lo podemos comprobar mostrando que, mientras esta última correlación es invariante bajo ciertas intervenciones, la primera no lo es.

Si pinto a todas las bolas de verde, las mayores seguirán sin atravesar el colador y así se romperá la correlación entre el color y la capacidad de pasar por los agujeritos de ese instrumento. Pero, si agrando los agujeros del colador lo suficiente, las bolas rojas van a pasar por ellos aun sin ser verdes. La relación entre tamaño y capacidad de pasar por los agujeros del colador se habrá mantenido y la correlación entre el color y esa capacidad, otra vez, se habrá perdido. La correlación (2) entre el tamaño de las bolas y la capacidad de pasar por colador se conserva en las intervenciones sobre los orificios de ese instrumento: es una regularidad causal. La correlación entre el color y esa capacidad, en cambio, no se conserva en intervenciones sobre dicho color: es una distribución contingente.

Los invariantes accidentales se rompen fácilmente cuando las variables por ellas correlacionadas son manipuladas (cf. Woodward, 2003, p. 259). En cambio, los invariantes causales resisten mejor esas manipulaciones. Por eso Woodward (cf. 2003, p. 16) afirma que la idea de invariancia bajo intervenciones está llamada a cumplir la tarea de distinguir entre generalizaciones causales y accidentales que, en otros enfoques de la explicación causal, es desempeñada por la noción de ley de la naturaleza. En la concepción experimental de la causación, (2) es a (1), lo que el principio de Arquímedes es a "todos los salvavidas del Titanic eran de corcho" en la concepción nomológica de la causación y de la explicación causal.

Pero, como el ejemplo de la radio ya lo mostró, y Woodward (cf. 2003, p. 17) lo apunta, el hecho de que una generalización sea o no causal "es llamativamente independiente de si ella satisface o no muchos de los criterios tradicionales de nomicidad, tales como la ausencia de excepciones, la amplitud de alcance, y el grado de integración teórica". Woodward afirma, incluso, que: "la mayor parte de esos criterios no son útiles, ni para entender qué es lo distintivo de las leyes, ni para entender las características que caracterizan a las generalizaciones explicativas, sea en el caso de las ciencias especiales o en disciplinas como la física o la química" (2003, p. 266). Bajo este punto de vista, el mayor poder explicativo, causal, del principio de Arquímedes no deriva de su universalidad, sino de su estabilidad e invariancia bajo intervenciones.

Como dice Woodward, "es la invariancia y no la nomicidad que es crucial para la explicación” (2003, p. 259). "La noción de invariancia es más adecuada que la de nomicidad para capturar las características distintivas de muchas generalizaciones que describen relaciones causales y que figuran en explicaciones" (2003, p. 17); y "parte del 
atractivo de la noción de invariancia es que ella promete un tratamiento más satisfactorio de las generalizaciones en las ciencias especiales que la oposición ley-accidente" (p. 24,0). No siendo como el principio de Arquímedes, los invariantes involucrados en las explicaciones causales de esas ciencias, pueden quizá ser como el principio que rige el control del volumen de nuestra radio. La estabilidad bajo intervenciones de los invariantes causales puede ser mayor o menor; y su fuerza explicativa, insisto, es directamente proporcional a esa estabilidad.

\section{UN MOSAIGO DE INVARIANTES ANTES QUE UN SISTEMA DE LEYES GAUSALES}

Nancy Cartwright (cf. 1999, p. 31) sugirió la alternativa de pensar al mundo como pautado por un mosaico (patchwork) de leyes; y propuso llamar a esa posición "pluralismo nomológico metafísico, como siendo "la doctrina según la cual la naturaleza está gobernada, en diferentes dominios, por diferentes sistemas de leyes, no necesariamente relacionados entre sí, de forma no sistemática o uniforme". Ese pluralismo se opondría al fundamentalismo: posición que consistiría en pensar al mundo como ordenado por un sistema único de leyes cuya base estaría en unas pocas leyes fundamentales o en una única ley totalizadora. Las tesis de Woodward sobre la causación, por su parte, permiten pensar al mundo como sujeto a un heteróclito mosaico de invariantes causales. La naturaleza estaría gobernada, en diferentes dominios y en diferentes momentos, por distintos invariantes - algunos de ellos de rango nómico - que no obedecen a una única ordenación jerárquica.

Independientemente de lo que pueda decirse a ese respecto cuando se piensa en las leyes físicas, creo que cuando aludimos a los invariantes que rigen a los fenómenos organísmicos, la idea del mosaico de invariantes parece definitivamente más plausible que el fundamentalismo. La biología teórica puede aspirar legítimamente a elucidar los principios fundamentales que regulan la organización (cf. Elsasser, 1987, p. 24, y la forma de todos los seres vivos (cf. Webster \& Goodwin, 1996, p. 125); pero no creo que nadie espere que la miríada de invariantes causales que gobiernan los más diversos fenómenos organísmicos y sub-organísmicos, puedan transformarse en teoremas de los axiomas de una teoría general del organismo como las alguna vez entrevistas por Wiesser (1962) y Elsasser (1969). Dichas teorías estarían más atentas a la coherencia e integración organizacional de los subsistemas orgánicos que a las conexiones causales particulares entre los eslabones de los distintos procesos orgánicos; y, por esa razón, los principios más generales de dicha teoría no serían causales: serían organizacionales.

Carl Craver (cf. 2007, p. 228) ya usó la imagen del mosaico para caracterizar el desarrollo de la neurociencia y el modo en el que dentro de ella se van articulando los 
resultados de las más diversas investigaciones. Yo creo que esa imagen vale para toda la biología funcional; y quizá para todas las disciplinas que, atendiendo a la ya mencionada dicotomía entre disciplinas baconianas y galileanas propuesta por Kuhn, también merezcan el calificativo de baconianas. Ambos tipos de ciencias no sólo se distinguen por la mayor importancia que las primeras le dan al control experimental de los fenómenos y las segundas a la subsunción de esos fenómenos dentro de grandes marcos teóricos; sino que también se distinguen por su modo de desarrollo.

Quiero decir: las ciencias baconianas avanzan por acumulación de resultados, construyendo paso a paso un amplio mosaico; y en ellas, a veces, la mano parece llegar antes que el concepto. Las ciencias galileanas, en cambio, parecen avanzar por grandes unificaciones teóricas. Así, mientras éstas dan esperanzas al fundamentalismo, las baconianas se llevan bien con un mundo modular, y, así, más fácilmente manipulable. Y esto es así aunque, a posteriori, se puedan ensayar reconstrucciones en los que los resultados obtenidos de forma relativamente aislada y fragmentaria puedan representarse como elementos de un único sistema teórico (cf. Lorenzano C., 2010).

Pero, más allá de esas posibles generalizaciones, lo cierto es que el conocimiento de la biología funcional realmente existente es, básicamente, una acumulación, no muy sistemática, de esos invariantes; y era a una parte de tales invariantes a los que aludía Claude Bernard (1984 [1865], p. 109) cuando se refería a leyes específicamente fisiológicas. Para él una ley no era más que "una relación numérica invariable entre dos fenómenos" (Bernard, 1984 [1865], p. 128). Cualquier regularidad causal, pasible de ser formulada como una correlación matemática constante, que permitiese controlar la ocurrencia, la intensidad y la frecuencia del efecto, manipulando la ocurrencia, la intensidad y la frecuencia de la causa (cf. Bernard, 1984 [1865], p. 108), sería, bajo ese punto de vista, una ley. Sin estar muy preocupado con la universalidad de la correlación causal establecida por una regularidad fisiológica, Bernard estaba dispuesto a llamar "ley" a cualquier invariante causal; aun cuando el mismo valiese para un único taxón.

Para Bernard, ciertamente, la correlación entre ritmo cardiaco y actividad física era una ley fisiológica. La cuestión terminológica, sin embargo, es aquí secundaria, y puede ocultarnos una cuestión epistemológica más interesante. Sin negar que todo fenómeno fisiológico pudiese ser explicado en virtud de causas próximas de carácter puramente químico y físico, y sin querer desmarcarse de un encuadramiento fisicalista, Claude Bernard (cf. 1984, [1865], p. 110) también insinuaba un punto de vista sobre la explicación causal fisiológica contrario a la supuesta heteronomía explicativa de la biología experimental (cf. Goodfield, 1987, p. 137-9). Para él, explicar en Fisiología era situar un fenómeno dentro de un invariante que permitiese su control experimental. 


\section{Colofón: LA GUESTIÓN DEL REDUGGIONISMO}

Negar la heteronomía explicativa de la biología funcional no implica desconocer que muchas de las explicaciones causales formuladas en ese dominio de investigación, estén articuladas por invariantes locales que pueden llegar a ser considerados como casos, o aplicaciones, de leyes físico-químicas; aunque eso no sea condición sine qua non para que tales invariantes puedan ser considerados explicativos. Pero, además de ser compatible con el reconocimiento de la posibilidad de ese tipo de vinculación entre conocimiento biológico y conocimiento físico - químico, la negación de la heteronomía explicativa de la biología funcional, también es compatible con el reconocimiento de que, muchas veces, ese descenso a lo físico-químico, a lo más básico, puede ser considerado como progresivo y lucrativo en términos cognitivos.

Muchas veces, tal como Woodward (cf. 2010, p. 317) lo ha señalado, los invariantes causales encontrados en las diferentes ciencias especiales son menos estables bajo manipulación, y menos precisos, que los invariantes físico-químicos. Por eso, en esas ciencias puede ser útil apelar a esos invariantes más básicos y más estables para así explicar los fenómenos en estudio. Podemos decir que las generalizaciones cimentadas en propiedades más fundamentales son comúnmente, aunque no siempre, más estables y más precisas que las generalizaciones formuladas en términos de propiedades más sobrevenientes (cf. Mitchel, 2009, p. 58). Pero eso no implica que dicho recurso a lo más básico sea el objetivo explicativo fundamental de esa ciencia especial. Si el Biólogo desciende a la infraestructura molecular del fenómeno biológico; lo hace, no con el objetivo de disolver dicho fenómeno en la legalidad físico-química, sino sólo para explicar ese fenómeno biológico en tenemos de invariantes causales más precisos y estables.

Bajo esta última perspectiva, la física y la química serían solamente instrumentos de la biología funcional; y es posible que, en ocasiones, ese descenso a la infraestructura molecular sea cognitivamente contraproducente: si ese descenso es medio y no fin, eso puede ocurrir. En algunos casos, quizá, mantenerse en el nivel de las propiedades propiamente biológicas puede permitirnos establecer relaciones causales más estables y un control de los fenómenos más afinado que el que nos permitiría el recurso a las propiedades más simple y elementales (cf. Caponi, 2015). Eso es lo que sostuvo Walter Elsasser (cf. 1987, p. 14.3), apelando no ya a un vitalismo trasnochado, sino a la más pura y simple experiencia laboratorial; $y$, también, a consideraciones sobre nuestras capacidades de computar la información que tendría que ser llevada en cuenta para dar una explicación molecular de fenómenos realmente organísmicos.

La perspectiva de Woodward permite abrir un crédito de plausibilidad a esa posición. Si hay explicación causal sin ley causal, podemos negar que la única posibilidad de explicar causalmente los fenómenos biológicos esté en las leyes causales que 
para ese fin presten la física o la química. Además, si la clave de la explicación causal no está en la propia legalidad, y sí en la estabilidad bajo manipulaciones experimentales, se puede llegar a pensar que, en ocasiones, y dependiendo de qué es lo que en cada caso queremos realmente saber, la estrategia reduccionista puede no ser la más promisora. El descenso a lo molecular puede impedirnos ver invariantes causales que se serían más visibles en un nivel menos básico (cf. Craver, 2007, p. 227): más propiamente organísmico.

El verdadero objetivo cognitivo de toda la Biología Funcional es entender el funcionamiento y la constitución del organismo; y no mostrar su (por nadie discutida) sujeción a la legalidad físico-química. Eso ya lo había apuntado el propio Claude Bernard (1984 [1865], p. 137); y las argumentos que a ese respecto formularon Kurt Goldstein (1951, p. 340) y Merleau-Ponty (1953, p. 215) siguen vigentes. La posibilidad de que existan casos en los que las explicaciones no-reductivas cumplan mejor con ese cometido que las explicaciones moleculares, ya alcanza para desmentir la heteronomía explicativa de la biología funcional. Porque así ya estamos reconociendo que la estrategia reduccionista, conforme ya dije, es medio, y no fin, de ese universo de las ciencias biológicas.

Nótese, por fin, que al decir esto último no estoy repitiendo el argumento según el cual, debido a la perspectiva funcional que rige sus indagaciones, la biología molecular no llegaría constituir un movimiento de reducción explicativa de lo biológico a lo físico-químico (cf. Kinkaid, 1990). Ése ha sido un argumento esgrimido por Rosenberg (2008, p. 515). La biología molecular, observa este autor, ya contiene enunciados funcionales que, precisamente en virtud de ese contenido funcional, serían irreductibles a los enunciados puramente causales de la química orgánica. Pero Rosenberg afirma eso porque, aceptando la concepción etiológica del concepto de función, él piensa que solamente se puede atribuir funciones a elementos modelados por la selección natural (cf. Rosenberg, 2006, p. 137-8). En cambio, si se rechaza esa concepción del concepto de función (cf. Caponi, 2012c, p. 28), y se acepta la concepción procesal, o sistémica, del concepto de función (Caponi, 2012c, p. 38), se puede considerar que todo proceso y cualquier proceso causal es pasible de ser analizado funcionalmente (cf. Caponi, 2012c, p. 40), el argumento pierde parte de su fuerza: puede articularse un discurso funcional legítimo referido a procesos inorgánicos (cf. Caponi, 2012c, p. 91).

En sí mismo, el hecho de que la biología molecular se articule con base en una perspectiva funcional, no es, por lo que acabo de decir, un argumento demasiado decisivo en contra de la posibilidad de que ella opere como una vía de reducción explicativa de lo biológico a lo físico-químico (cf. Caponi, 2014,b, p. 22). En cambio, el argumento anti-reduccionista cuya posibilidad yo aquí sólo estoy sugiriendo, va en otra dirección: apunta a una posible limitación de las pretensiones de la propia biología 
molecular. Ésta suele ser entendida como el vector de progreso de todas esas disciplinas que, siguiendo a Mayr, yo englobé bajo la rúbrica de "biología funcional"; y creo que se podrían relativizar esas pretensiones. Descender a la esfera de lo molecular puede no ser un desiderátum constitutivo de la biología funcional; sino sólo un recurso, muchas veces el mejor, para cumplir con objetivos cognitivos anteriores e independientes de esa reducción.\$

\title{
Gustavo Caponi
}

Departamento de Filosofia, Universidade Federal de Santa Catarina,

Florianópolis, Brasil. gustavoandrescaponi@gmail.com

\section{On the supposed explanatory heteronomy of functional biology}

\begin{abstract}
In accordance with a widespread point of view, aligned with the nomological conception of causal explanation, Functional Biology is subjected to a regime of explanatory heteronomy under which, organic phenomena should be causally explained by using laws of Physics and Chemistry. Against this perspective, the experimental conception of causation allows us to understand the nature of many biological explanations that, without make any reference to causal laws - physical, chemical or of other nature - are legitimized because they permit the experimental control of phenomena that have to do with the functioning and development of organisms. These explanations involve local invariants that often, but not necessarily, may be characterized as instances of physical and chemical laws.
\end{abstract}

KEYwords • Causal invariants. Causal laws. Explanatory heteronomy. Woodward. James.

\section{REFERENGIAS BIBLIOGRÁFICAS}

Abrantes, P. (Ed.). Filosofia da biologia. Artmed: Porto Alegre, 2011.

BAEDKE, J. Causal explanation beyond the gene: manipulation and causality in epigenetics. Theoria, 74, p. $15^{3-74,}, 2012$.

Barreau, H. (Ed.). L'explication dans les sciences de la vie. Paris: CNRS, 1983.

Bechtel, W. Mechanism and biological explanation. Philosophy of Science, 78, p. 533-57, 2011.

Beebe, H.; Hitchcock, C. \& Menzies, P. (Ed.). The Oxford handbook of causation. Oxford: The Oxford University Press, 2009.

Bernard, C. Introduction a l'étude de la médicine expérimentale. Paris: Flammarion, 1984 [1865]. 


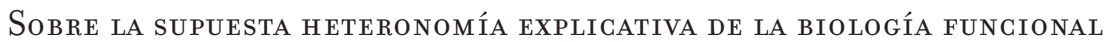

Blanco, D. Primera aproximación estructuralista a la teoría del origen común. Ágora, 31, 2, p. 171-94, 2012.

Caponi, G. Experimentos en biología evolutiva: ¿qué tienen ellos que los otros no tengan? Episteme, 16, p. 61-97, 2003.

. Réquiem por el centauro: aproximación epistemológica a la biología evolucionaria del desarrollo. México:

Centro Lombardo Toledano, 2012a.

. Linajes y sistemas: dos tipos de individuos biológicos. Scientiae Studia, 10, 2, p. 243-68, 2012b.

. Função e desenho na biologia contemporânea. São Paulo: Associação Filosófica Scientiae Studia/Edi-

tora $34,2012 \mathrm{c}$.

El concepto de presión selectiva y la dicotomía próximo-remoto.Aurora, 25, 36, p. 197-216, 2013a.

. A noção de causa e a ideia de lei causal. In: Menna, S. (Ed.). Conhecimento e linguagem. Porto Alegre:

Redes, 2013b. p. 95-106.

. Causas sin ley y leyes sin causa en la explicación biológica. Princípios, 20, 34, p. 19-54, 2013c.

. El caleidoscopio de Darwin: los invariantes selectivos como articuladores causales de la teoría de la selección natural. Scripta Philosophiae Naturalis, 5, p. 25-48, 2014a.

. Esboço de uma taxonomia dos empreendimentos reducionistas. Filosofia e História da Biologia , 9, 1, p. 19-38, 2014,b.

. La explicación causal biológica en el marco de una ontología fisicalista. Filosofia e História da Biologia, 10, 1, p. 37-4, 2015 .

CARTWRight, N. How the laws of physics lie. Oxford: Oxford University Press, 1983.

The dappled world. Cambridge: Cambridge University Press, 1999.

Craver, C. Structure of scientific theories. In: Maghamer, P. \& Silberstein, M. (Ed.). The Blackwell guide to philosophy of science. Oxford: Blackwell, 2002. p. 55-79.

Craver, C. Explaining the brain. Oxford: Clarendon Press, 2007.

DARden, L. (Ed.). Reasoning in biological discoveries. Cambridge: Cambridge University Press, 2006.

Darden, L. et al. Thinking about mechanisms. In: Darden, L. (Ed.). Reasoning in biological discoveries. Cambridge: Cambridge University Press, 2006. p. 13-39.

Delsol, M. \& Perrin, L. Médecine et biologie: quelle logique? Paris: Masson, 2000.

Elsasser, W. Átomo y organismo: nuevo enfoque de la biología teórica. México: Siglo xxi, 1969.

Reflections on a theory of organism. Baltimore: John Hopkins University Press, 1987.

Futuyma, D. \& Bennett, A. The importance of experimental studies in evolutionary biology. In: GarLand, T. \& Rose, M. (Ed.). Experimental evolution: concepts, methods, and applications of selection experiments. Berkeley: University of California Press, 2009. p. 15-3o.

Gachelin, G. (Ed.). Les organismes modèles dans la recherche médicale. Paris: PUF, 2006.

Garland, T. \& Rose, M. (Ed.). Experimental evolution: concepts, methods, and applications of selection experiments. Berkeley: University of California Press, 2009.

Glennan, S. Mechanisms. In: Beebe, H.; Нitchсock, C. \& Menzies, P. (Ed.). The Oxford handbook of causation. Oxford: The Oxford University Press, 2009. p. 315-25.

Gilbert, S. Biologia do desenvolvimento. Ribeirão Preto: Sociedade Brasileira de Genética, 1994.

Ginnobili, S. Función como concepto teórico. Scientiae Studia, 9, 4, p. 185-214, 2011.

Goldstein, K. La structure de l'organisme. Paris: Gallimard, 1951.

Goodfield, J. El desarrollo de la fisiología científica. México: UNAM, 1987.

Gradmann, C. Maladies expérimentales: les expériences sur l'animal aux débuts de la bacteriologie médicale. In: Gachelin, G. (Ed.). Les organismes modèles dans la recherche médicale. Paris: PUF, 2006. p. $75^{-9} 94$.

Hempel, G. La explicación científica. Buenos Aires: Paidos, 1979 [1965]. 
Hookwayookway, C. (Ed.). Minds, machines \& evolution. Cambridge: Cambridge University Press, 1986. Huld, D. Historical entities and historical narratives. In: HookwaYookway, C. (Ed.). Minds, machines \& evolution. Cambridge: Cambridge University Press, 1986. p. 17-422.

Јасов, F. La lógica de lo viviente. Barcelona: Laia, $197^{3}$.

KinKaId, H. Molecular biology and the unity of science. Philosophy of Science, 57, p. 575-93, 1990.

Kunn, T. The essential tension. Chicago: Chicago University Press, 1977.

Lorenzano, C. Estructuras y mecanismos en la fisiología. Scientiae Studia, 8, 1, p. 41-67, 2010.

Lorenzano, P. Sobre leyes en biología. Episteme, 3, 7, p. 261-272, 1998.

. Leyes fundamentales y leyes de la biología. Scientiae Studia, 5, 2, p. 185-214, 2007.

. Leis e teorias em biologia. In: Abrantes, P. (Ed.). Filosofia da biologia. Artmed: Porto Alegre, 2011. p. $5^{3-82}$.

Lubchenco, J. \& Real, L. Manipulative experiments as tests of ecological theory. In: Real, L. \& Brown, J.

(Ed.). Foundations of ecology. Chicago: The University of Chicago Press, 1991. p. 715-33.

Machamer, P. \& Silberstein, M. (Ed.). The Blackwell guide to philosophy of science. Oxford: Blackwell, 2002.

MaYr, E. Cause and effect in biology. Science, 134, p. 1501-6, 1961.

The growth of biological thought. Cambridge: Harvard University Press, 1982.

Menna, S. (Ed.). Conhecimento e linguagem. Porto Alegre: Redes, 2013.

Menzies, P. The causal structure of mechanisms. Studies in History and Philosophy of Biological and Biomedical Sciences, 43, p. 796-805, 2012.

Merleau-Ponty, M. La estructura del comportamiento. Buenos Aires: Hachette, 1953.

Mitcheld, S. Unsimple truths. Chicago: The University of Chicago Press, 2009.

Morange, M. La vie, l'évolution et l'histoire. Paris: Odile Jacob, 2011.

PAPP, D. Filosofía de las leyes naturales. Buenos Aires: Troquel, 1980.

PARK, T. Experimental studies of interspecies competition. Ecological Monographs, 18, 2, p. 267-3o7, 1948.

Popper, K. La lógica de la investigación científica. Madrid: Tecnos, 1962 [1934].

Psillos, S. Causation and explanation. Stockfields: Acumen, 2002.

Psillos, S. \& Curd, M. (Ed.). Companion to philosophy of science. London: Routledge, 2008.

Raerinne, J. Stability and lawlikeness. Biology \& Philosophy, 28, p. 833-51, 2013.

Real, L. \& Brown, J. (Ed.). Foundations of ecology. Chicago: The University of Chicago Press, 1991.

Roger, J. Biologie du fonctionnement et biologie de l'évolution. In: BArreau, H. (Ed.). L'explication dans les sciences de la vie. Paris: CNRS, 1983. p. 135-60.

Rомо, A. Claude Bernard. México: Siglo xxi, 2006.

Rosenberg, A. Darwinian reductionism. Chicago: University of Chicago Press, 2006.

. Biology. In: Psillos, S. \& Curd, M. (Ed.). Companion to philosophy of science. London: Routledge, 2008. p. $5^{11-9}$.

Smart, J. Philosophy and scientific realism. New York: Routledge, 1963.

SовеR, E. The nature of selection. Chicago: Chicago University Press, 1984 .

Thagard, P. How scientists explain disease. Princeton: Princeton University Press, 1999.

UjнÁzy, E. et al. Teratology - past, present and future. Interdisciplinary Toxicology, 5, 4, p. 163-8, 2012.

Valery, P. L'homme et la coquille. Varieté 3, 4 \& 5. Paris: Folio, 2002 [1944]. p. 541-69.

Von Wright, H. Explicación y comprensión. Madrid: Alianza, 1980.

Waters, K. Causal regularities in the biological world of contingent distributions. Biology \& Philosophy, 13, p. 5-36, 1998.

Weber, M. Philosophy of experimental biology. Cambridge: Cambridge University Press, 2004.

Webster, G. \& Goodwin, B. Form and transformation. Cambridge: Cambridge University Press, 1996.

Wieser, W. Organismos, estructuras, máquinas. Buenos Aires: Eudeba, 1962. 
Sobre LA SUPUESTA HETERoNomía EXPLIGATIVA DE LA BIOLOGÍA FUNGIONAL

Woodward, J. Law and explanation in biology. Philosophy of Science, 68, p. 1-20, 2000.

. What is a mechanism? Philosophy of Science, 69, p. S366-77, 2002.

Making things happen: a theory of causal explanation. Oxford: Oxford University Press, 2003.

. Agency and interventionist theories. In: Beebe, H.; Нitchcock, G. \& Menzies, P. (Ed.). The Oxford handbook of causation. Oxford: The Oxford University Press, 2009. p. 234,-62.

. Causation in biology. Biology \& Philosophy, 25, p. 287-318, 2010.

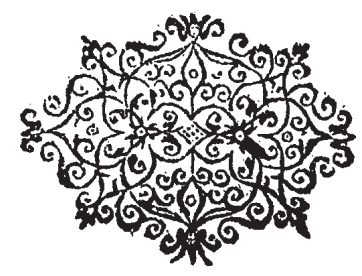

